\title{
MIEDOS MASCULINOS Y MUTILACIÓN GENITAL FEMENINA ${ }^{1}$
}

\author{
José Martín Amenabar Beitia ${ }^{2}$
}

Resumen: El presente trabajo constituye una aproximación psicológica a la mutilación genital femenina, dándose a conocer las motivaciones, expectativas y fantasías que la sustentan y que, por cierto, ponen de relieve como elemento medular el miedo del hombre ante la sexualidad femenina. El análisis del mito de la vagina dentada es muy ilustrativo al respecto. Por otra parte, como ejemplificación de la problemática abordada, se toma en consideración el relato aportado por una mujer sobre la mutilación genital padecida siendo niña y el gran sufrimiento que ello le causó. Y, por último, se incorporan ciertas reflexiones que inspiraron este artículo. Palabras clave: Mutilación genital femenina, clitoridectomía, infibulación, miedo a la mujer, mitología, vagina dentada, sexualidad femenina.

\section{Title in English: Male fears and female genital mutilation}

Abstract: This paper takes a psychological approach to genital feminine mutilation, showing the motivations, expectations and fantasies that sustain it, and which demonstrate that men's fear of feminine sexuality is a fundamental element underpinning the practice. Analysis of the myth of the toothed vagina is illustrative and pertinent. It must be viewed alongside a woman's evidence concerning her genital mutilation in infancy, and her ongoing resultant suffering. In conclusion, mention will be made of some reflections that prompted this paper. Key words: Genital feminine mutilation, clitoridectomy, infibulation, fear of the woman, mythology, toothed vagina, feminine sexuality.

\section{Introducción}

La sexualidad es parte constitutiva del ser humano. Somos seres sexuados y sexuales que, a través de la estimulación corporal, estamos en condiciones de obtener placer, en solitario y en compañía, de una y mil maneras. Las posibilidades de satisfacción y expresión sexual pueden ser muy diversas, nuestra forma de vivir y de

\footnotetext{
${ }^{1}$ Fecha de recepción: 30/07/2013

Fecha de aceptación: 06/10/2013

${ }^{2}$ Profesor Colaborador, Departamento de Personalidad, Evaluación y Tratamiento Psicológico, Universidad del País Vasco, San Sebastián, España, $\triangle$ josemartin. amenabar@ehu.es.
} 
relacionarnos sexualmente y de definirnos al respecto también, en función de nuestro desarrollo psicosexual y de los avatares de la vida, dependiendo de las significaciones individuales y colectivas que se vayan gestando. Pero independientemente de las diferentes prácticas que se puedan plantear o llevar a cabo, tendríamos que considerar que cada ser humano como sujeto sexuado y sexual que es, desde su peculiaridad personal, debería tener la oportunidad y la libertad de desarrollarse y expresarse sexualmente de acuerdo con lo que sienta y desee, y que su placer tan solo tenga como límite la libertad y el deseo del otro. No obstante, en no pocas ocasiones, en distintos lugares y tiempos históricos, se han ideado rígidos dispositivos socioculturales para normativizar las prácticas, los roles y las identidades sexuales, llegándose incluso a intervenir por mandato o presión sobre la corporalidad, tal como ocurre con la "propuesta" de la extirpación o mutilación parcial o total de los órganos genitales por razones no terapéuticas.

El tema de la mutilación genital femenina, una práctica que se halla profundamente arraigada en ciertas sociedades desde hace mucho tiempo, desde antes de la aparición del Islam y del Cristianismo, puede afectar gravemente, causando gran sufrimiento físico y emocional, a lo largo de su vida (sexual) a la mujer. Un sufrimiento que atenta contra la libertad y los derechos humanos, y que resulta tanto más dramático si cabe cuando las víctimas son niñas y han sido conducidas, bajo seducciones y ocultamientos, a participar en un rito que les marcará en el cuerpo y en el alma, con la idea sostenida colectivamente de que es "por su propio bien", para favorecer y propiciar la integración en una comunidad que les reconocerá en adelante como "verdaderas" mujeres, mujeres limpias.

Este artículo lo he escrito con la intención de sensibilizar al lector en el sufrimiento físico y emocional causado a muchas niñas y mujeres por motivaciones rituales, al mismo tiempo que trato de llamar la atención sobre las motivaciones, expectativas y fantasías que sustentan tal forma de intervención y control sobre el cuerpo (y la sexualidad). La tesis que planteo en el artículo se inspira en la labor de una psicoanalista pionera, Karen Horney (1932), quien tuvo la audacia de contemplar la sexualidad femenina desde una vertiente genuinamente femenina y no como una falta $o$ 
falla de lo masculino, además de sostener que ciertas conductas varoniles encubren por compensación un gran temor a la mujer.

Para llevar adelante los objetivos de mi artículo me ha parecido conveniente apoyarme en el testimonio de alguna mujer que haya padecido en su infancia el drama de la mutilación genital por motivos rituales. Cualquiera que se adentre en Internet y en la consulta bibliográfica puede encontrar muchos casos ilustrativos que nos sirvan como ejemplificación de las consecuencias físicas y psicológicas de la mutilación genital así como de las causas socioculturales, racionalizaciones y justificaciones que operan en su mantenimiento. Hemos de estar muy agradecidos a las mujeres que han roto las barreras del silencio y han decidido ofrecernos su testimonio, pues con su valentía están ayudando a señalar el problema, para que lo conozcamos y reconozcamos, y así podamos luchar eficazmente por su erradicación. Cada testimonio de mutilación genital (yo me he basado en varios extractos del relato que refiere Waris Dirie, una famosa modelo somalí que padeció esta intervención cuando apenas contaba con cinco años de edad) nos sirve para crear conciencia y sensibilizar al respecto así como para reflexionar sobre sus causas y poder pensar en propuestas de solución.

\section{El rito de la mutilación genital}

La mutilación genital femenina se lleva a cabo en la mayoría de los casos durante la infancia, a veces a edades muy tempranas, entre los 4 y los 8 años, o incluso antes, en determinadas comunidades pocos días después del nacimiento, extendiéndose generalmente hasta los 14 ó 15 años; ocasionalmente se lleva a cabo en la etapa adulta. Como lo recuerda la propia Waris Dirie:

[...] todas las chicas somalíes aguardan expectantes la ceremonia que las transformará de niñas en mujeres. (Dirie 1998: 49).

La noche antes de mi ablación, mi madre me dijo que no bebiera demasiada agua o leche, para que no tuviera que hacer mucho pis [...]. Aquella noche, la familia me 
mimó más y me dio más de cenar que de costumbre. Ésa era la tradición que había observado a lo largo de los años y que me hacía sentir celos de mis hermanas mayores. (Dirie 1998: 52-53)

La niña puede estar muy ilusionada por participar en la ceremonia de su "conversión" en mujer, que ha podido estar esperando y anhelando como un gran objetivo en su vida, como algo muy especial y atractivo, por la nueva consideración social que supone en su vida y por su asociación con regalos y mimos. Unas atenciones especiales que, según Tractenberg, además de dispensársele como muestra de celebración de su aceptación o reconocimiento público, constituyen la ocultación maníaca mediante la cual el yo guarda obediencia "a los mandatos destructivos del superyó" (Tractenberg 1972: 59).

La práctica tradicional de la mutilación genital femenina forma parte de un proceso de socialización e inserción en la comunidad, por el que se fija la identidad de género y se generan mayores posibilidades para contraer matrimonio y formar una familia. Porque mientras no se pasa por este rito, o para quienes no lo transitan, hay dificultades, cuando no marginación o total rechazo. De hecho, hay hombres que no quieren casarse con una mujer que no ha sido sometida a la mutilación genital, por considerarla, dicen, impura o poco femenina: "En Somalia se cree que entre las piernas de las chicas existe algo malo, partes del cuerpo con las que nacemos, pero que no son limpias. Estas cosas tienen que extirparse" (Dirie 1998: 49):

Mamá cogió un trozo de raíz de un viejo árbol [...]; se sentó detrás de mí y puso mi cabeza sobre su pecho; sus piernas me rodearon y yo le rodeé los muslos con los brazos. Mi madre me puso la raíz entre los dientes. -Muérdela [...]. Mamá se inclinó sobre mí y me susurró: -Sabes que no puedo sostenerte. Estoy sola, así que trata de ser una buena chica, nena. Sé valiente para tu mamá, y será rápido. (Dirie 1998: 53-54)

Miré entre mis piernas y vi que la gitana se estaba preparando [...]. Clavé mi mirada en ella, porque quería saber con qué iba a cortarme [...] y extrajo una cuchilla de navaja, rota. La hizo girar y la examinó. El sol acababa de salir y la luz permitía distinguir los colores, pero no los detalles; sin embargo, noté sangre seca en su filo desigual. La gitana escupió en ella y se la secó en el vestido. Mientras 
ella la limpiaba, mi mundo se oscureció, pues mi madre me había vendado los ojos con un pañuelo. (Dirie 1998: 54)

Lo siguiente que percibí fue cómo me cortó la carne, los genitales. Sentí la hoja embotada atravesar mi piel, de arriba abajo, serrándola [...]. Es como si alguien te rebanara el muslo o te cortara el brazo, sólo que lo están haciendo en la parte más sensible de tu cuerpo. Sin embargo, no me moví ni un centímetro, [...] quería que mamá se sintiera orgullosa de mí. Permanecí sentada, como hecha de piedra, diciéndome que cuanto más me moviera, tanto más duraría la tortura. Por desgracia, mis piernas empezaron a estremecerse, a temblar sin control, y recé, Dios, por favor, que acabe pronto. Y así fue, porque me desmayé. (Dirie 1998: 5455)

Cuando volví en mí creí que habíamos terminado, pero apenas había comenzado lo peor. Me habían quitado la venda y a su lado la Asesina había apilado un montón de espinas de acacia; las usó para perforarme la piel y luego pasó un fuerte hilo blanco por los agujeros y me cosió. Mis piernas estaban totalmente entumecidas, pero el dolor entre ellas era tan intenso que deseé morir. (Dirie 1998: 55)

Creí que el tormento había acabado, hasta que tuve que orinar, y entonces entendí el consejo de mi madre de que no bebiera demasiada agua o leche [...]. La primera gota me escoció como si un ácido me estuviese corroyendo la piel. (Dirie 1998: 5556)

Las palabras de Waris Dirie son altamente emotivas e impactantes, nos trasladan a una ceremonia tremendamente dolorosa y traumática, con consecuencias negativas a corto y largo plazo, practicada por tradición y costumbre sobre unas personas que, por su edad y situación de vulnerabilidad, se ven imposibilitadas para defenderse o escapar del destino que les aguarda. Una vivencia ocupadora del cuerpo y del alma. De hecho, muchas mujeres nunca llegan a recuperarse del trauma que representó en su vida la mutilación genital. Aunque la herida física haya cicatrizado, no lo ha hecho la herida psíquica. Llevan grabado, con una marca imborrable en sus cuerpos, y en sus mentes, el acontecimiento traumático, padeciendo y reviviendo un sufrimiento inextinguible. Hay mujeres que se sienten incompletas. O como bichos raros en comparación con otras mujeres que no han pasado por tal pesadilla. Y que por ello se sienten humilladas. Impotentes. Con rabia. ¿Acaso les informaron de las consecuencias que la mutilación genital podía suponerles? ¿Acaso podían negarse a que les practicaran tal intervención? ¿Acaso quienes organizaron y les practicaron la mutilación genital pensaron en el sufrimiento que causaban? 
Hay mujeres a quienes muchos años después les sigue asaltando el recuerdo de la mutilación genital con sus vívidas imágenes traumáticas, reviviendo la sensación de impotencia e indefensión en que se encontraron, la incomprensión experimentada por lo que estaba aconteciendo, o el sonido del instrumento empleado cortando sus partes íntimas. Un tremendo sufrimiento, un calvario, un horror, que además se ve acrecentado cuando resulta prácticamente imposible hablarlo o compartirlo con la gente, como si fuera un tema tabú que tenga que quedar en el espacio de la intimidad personal. Resulta llamativo que las mujeres no sometidas a la ablación se enfrentan en estas comunidades al drama de la exclusión social, con lo que de una manera u otra, pasando o sin pasar por la mutilación genital, para todas las mujeres parece inevitable el sufrimiento traumático vinculado con la sexualidad:

Después de que me cosiera la gitana, la orina y la sangre de la menstruación sólo podían salir por un minúsculo agujero del diámetro de una cerilla. (Dirie 1998: 56)

Mantuvieron mis piernas atadas durante más de un mes, a fin de que la herida cicatrizara. (Dirie 1998: 57)

Cada semana mi madre comprobaba si la herida cicatrizaba como era debido. Cuando me quitaron las ataduras pude mirarme por primera vez. Descubrí un trozo de piel totalmente lisa, excepto por una cicatriz en medio, como una cremallera, y esa cremallera estaba definitivamente cerrada. (Dirie 1998: 57-58)

Waris Dirie padeció una forma de mutilación genital extrema, la infibulación, también conocida como circuncisión faraónica, debido a que este tipo de mutilación genital, según se desprende del análisis de algunas momias, se efectuaba en el antiguo Egipto. Puesto que el orificio resultante para que fluya la orina y la sangre menstrual es diminuto, el día de la boda, con objeto de poder consumar el acto sexual, o más adelante durante el parto, suele practicarse la desinfibulación, a veces mediante un cuchillo.

De acuerdo con la Organización Mundial de la Salud (OMS), la mutilación genital femenina puede diferenciarse, según el grado de intervención corporal, en los siguientes grupos: 
1) “Clitoridectomía: resección parcial o total del clítoris (órgano pequeño, sensible y eréctil de los genitales femeninos) y, en casos muy infrecuentes, solo del prepucio (pliegue de piel que rodea el clítoris)" (OMS 2012). Este tipo de mutilación genital femenina lo contemplan algunos como similar o equivalente a la circuncisión masculina. Pero si nos atenemos al significado del término circuncidar, que, según la Real Academia Española, consiste en "Cortar circularmente una porción del prepucio a alguien", se aplicaría en todo caso a la clitoridectomía menos grave, cuando se interviene exclusivamente en el pliegue de piel que rodea el clítoris.

2) "Excisión: resección parcial o total del clítoris y los labios menores, con o sin excisión de los labios mayores" (OMS 2012).

3) "Infibulación: estrechamiento de la abertura vaginal para crear un sello mediante el corte y la recolocación de los labios menores o mayores, con o sin resección del clítoris" (OMS 2012).

4) “Otros: todos los demás procedimientos lesivos de los genitales externos con fines no médicos, tales como la perforación, incisión, raspado o cauterización de la zona genital" (OMS 2012).

Adentrémonos nuevamente en el relato de Waris Dirie. Ella dice lo siguiente:

Aunque sufrí como resultado de la ablación, tuve suerte. Podría haberme ido mucho peor, como les ocurría a menudo a otras chicas. En nuestro recorrido por Somalia conocíamos a otras familias y yo jugaba con sus hijas. Cuando los visitábamos de nuevo las chicas habían desaparecido. Nadie decía la verdad acerca de su ausencia y ni siquiera las mencionaban. Morían como resultado de la mutilación: desangradas, por la conmoción, por una infección o por el tétanos. (Dirie 1998: 58)

Apenas recuerdo a mi hermana Halemo. Tendría yo unos tres años cuando estaba con nosotros y al día siguiente ya no. Pero no entendía qué le había sucedido. Más tarde supe que, llegado su "momento especial", cuando la gitana la circuncidó, murió desangrada. (Dirie 1998: 58) 
La mutilación genital femenina suele realizarse con utensilios (tijeras, navaja, cuchilla, pedazo de cristal, tapa de una lata, etc.) y en condiciones higiénicas y sanitarias que dejan mucho que desear, lo que puede ocasionar infecciones, hemorragias y otras complicaciones, o la muerte, pues no todas las niñas sobreviven a la mutilación genital, tal como le sucedió a una de las hermanas de Waris Dirie.

La OMS (2012) informa que la mutilación genital femenina no es saludable, perjudicando a las niñas y mujeres de diversas maneras. Entre las consecuencias inmediatas que pueden darse se encuentran las siguientes: dolor intenso, hemorragias, sepsis, retención de orina, llagas abiertas en la región genital y lesiones de los tejidos genitales vecinos. Las consecuencias a largo plazo pueden consistir en infecciones vesicales y urinarias recurrentes, quistes, esterilidad, aumento del riesgo de complicaciones del parto y muerte del recién nacido, o necesidad de intervenciones quirúrgicas, por ejemplo, para corregir el procedimiento de sellado o estrechamiento de la abertura vaginal con objeto de permitir las relaciones sexuales y el parto.

\section{Proceso de inserción social y control sobre la sexualidad femenina}

Los padres que someten a sus hijas a la mutilación genital, siguiendo tradiciones ancestrales, lo hacen pensando que es por el bien de estas, con objeto de favorecer la adaptación o inserción social. Con la idea de que puedan llegar a ser todo lo que pueden llegar a ser en la sociedad a la que pertenecen. A este respecto son significativas las siguientes palabras de Waris Dirie:

[...] mi madre quería lo mejor para mí. Lo sé, yo misma soy madre. Todas las madres quieren lo mejor para sus hijos. Ella pensaba que con la mutilación me convertirían en una mujer, que propiciarían mi acceso a la sociedad de los adultos, que me darían la oportunidad de encontrar un marido, porque en nuestra sociedad no eres nadie sin marido. (Dirie 2005: 218) 
En determinadas sociedades suele afirmarse que todo ser humano tiene, en el momento de nacer, por naturaleza, un cierto grado de bisexualidad, que en el caso del niño se reflejaría en la existencia del prepucio y en el caso de la niña en su clítoris. Partiendo de la idea de que el clítoris es la parte genital masculina en el cuerpo de la mujer, un atributo corporal del otro sexo, su mutilación o extirpación es considerada como la vía por la cual la mujer llegaría a ser completamente o solamente femenina. La mutilación genital, dentro de esta concepción, se ve como la intervención necesaria para lograr la correspondencia total del cuerpo con el sexo, eliminándose así las supuestas impurezas o imperfecciones. Se entiende como el tránsito de una etapa con un organismo insuficientemente diferenciado en su masculinidad/feminidad a una etapa en que se habría accedido a la plena diferenciación sexual, para evitar confusiones identitarias y conductuales entre las personas. Tengamos en cuenta que en aquellas sociedades en que tradicionalmente las mujeres son sometidas a la ablación genital, los hombres son circuncidados. Al hombre se le extirparía el prepucio (considerado como labio vaginal, como componente femenino) y a la mujer el clítoris (contemplado como un pequeño pene, como componente masculino). Mitología de diferenciación nítida de género y funciones, con unos roles específicos a desempeñar en la sociedad. Rito de paso, por el cual se pretende exhibir la limpieza o pureza (de sexo). Y ser reconocido socialmente, "convertido" en un ser deseable. Porque mientras tanto, o hasta entonces, el repudio puede estar presente, y padecerse, en la cotidianeidad de las relaciones interpersonales. Por ejemplo, tal como comenta Waris Dirie:

Un amigo de mi padre -y su familia- viajaba siempre con nosotros. Era un viejo malhumorado, y cuando yo o mi hermana menor le incordiábamos, nos alejaba con un gesto de la mano, como espantando moscas, y para provocarnos decía: Apartaos de mí, chiquillas antihigiénicas, criaturas inmundas. ¡Ni siquiera os han circundado todavía! (Dirie 1998: 52)

La mutilación genital femenina, si bien es cierto que constituye una práctica favorecedora de la adaptación o inserción de la niña en su comunidad, para concretar su condición de género y otorgarle un reconocimiento social que le permita ser candidata 
al matrimonio y desarrollar los roles (femeninos) acordes con su cultura, por otra parte constituye una forma de control para doblegarla o silenciarla sexualmente, concediéndosele al hombre el papel dominante, el poder para conducir y administrar unilateralmente los tiempos y las acciones durante las relaciones sexuales.

En un estudio (El-Mouelhy y Johansen 2010) realizado en tres comunidades de Egipto acerca de las percepciones de hombres y mujeres con respecto a la mutilación genital femenina, se ha encontrado la creencia de que esta práctica resulta una vía necesaria y efectiva para asegurar la virtud de la mujer. Los informantes del estudio manifestaron que el deseo sexual de la mujer reside en el clítoris y que amputándolo decrecería tal deseo, con lo que se favorecería tanto la virginidad prematrimonial como la fidelidad matrimonial. La visión de películas pornográficas, particularmente populares entre los hombres jóvenes, habría reforzado la creencia de que la ausencia de mutilación genital conduce a las mujeres a la promiscuidad y a una sexualidad insaciable. Si bien es cierto que se piensa que la mutilación genital reduce el deseo sexual, no se cree que tenga un efecto negativo en el placer sexual de la mujer ni tampoco en la felicidad conyugal. La cuestión es que no se ha atribuido importancia al deseo sexual de la mujer, puesto que el deseo sexual y el inicio de las relaciones sexuales se consideran cosas del hombre. Además, hombres y mujeres utilizan la satisfacción y el placer sexual masculino como el principal criterio para juzgar que la vida sexual matrimonial es satisfactoria para la pareja. De todas maneras, las mujeres se sienten contentas con su vida sexual, poco relacionada con su experiencia de placer sexual mientras que aparece más relacionada con la pasión, el afecto, el trato amable y la ausencia de violencia doméstica, así como con factores socioeconómicos, tales como la seguridad económica. Algunas mujeres experimentan una considerable incomodidad durante las relaciones sexuales; no obstante, en raras ocasiones interpretan esto como consecuencia de la mutilación genital sino más bien con otras experiencias, especialmente con embarazos múltiples o con la debilidad del sistema inmunitario. Por otra parte, la mayoría de los hombres considera la felicidad sexual como una parte esencial de la felicidad matrimonial, y temen que la mutilación genital femenina 
reduzca su propio placer sexual, no sintiéndose preocupados de que pueda reducirse el placer en las mujeres.

Como se detecta en el estudio anterior, en las comunidades que se realiza algún tipo de mutilación genital femenina se cree que ello sirve para atemperar o debilitar el deseo sexual de la mujer, lo que a su vez serviría:

1) Para intentar salvaguardar la virginidad prematrimonial, algo que puede constituir un indicador valiosísimo a la hora de mantener el honor familiar. La infibulación, una especie de cinturón corporal de castidad, ofrecería, en este sentido, las máximas garantías. Como refiere Waris Dirie al hablar sobre sí misma: "Con esta brillante estrategia, se aseguraban de que no practicara el sexo hasta después de casarme y de que mi marido supiera que se casaba con una virgen" (Dirie 1998: 56), "Mis genitales se hallaban sellados, como un muro de piedra que ningún hombre podría penetrar hasta la noche de mi boda, cuando mi marido me rajaría con un cuchillo o me penetraría a la fuerza" (Dirie 1998: 58). Resulta estremecedor imaginar el intenso dolor, además del grado de humillación, que puede suponer la realización de la desinfibulación.

2) Para favorecer la fidelidad a su esposo o pareja, como una forma de prevenir la promiscuidad, desconfiándose que lo pueda hacer como prueba de amor o por decisión propia. A este respecto son llamativas las palabras de un imán, quien refiere lo siguiente:

Las mujeres no sometidas a ablación sienten la necesidad de yacer siempre con un hombre. Cuando el marido se va a trabajar, tienen que irse a la cama con algún otro porque no pueden resistirse. Nuestras mujeres, en cambio, son fieles y reservadas. Conviven con frecuencia en familias muy numerosas, pero ya puede haber diez hombres en la casa que ellas permanecerán fieles porque están circuncidadas. (Dirie 2005: 192)

3) Con la idea de que el esposo no se vea desbordado por las demandas sexuales de la mujer, especialmente cuando hablamos de culturas en que el hombre tiene derecho a la poligamia y se ve en la tesitura de tener que satisfacer sexualmente a varias 
esposas, además de tener que sostenerlas económicamente: "Los antropólogos han observado que entre los jíbaros de la cuenca alta del Amazonas, se creía que la escisión del clítoris podía mitigar la excesiva pasión sexual de las mujeres y dar a sus maridos un merecido descanso" (Blackledge 2003: 139).

Es sabido que actualmente la mutilación genital constituye una práctica habitual en numerosas sociedades o comunidades de más de veinte países de África y en varios países de Asia, y que en los países occidentales se ha detectado entre algunos inmigrantes aferrados a la cultura de origen, aunque, también es cierto que, en determinada época, tuvo lugar en Inglaterra, Estados Unidos, Francia y Alemania, en este caso como una propuesta médica y no como costumbre social o comunitaria:

En la segunda mitad del siglo XIX, durante un período de más de diez años, el cirujano británico Isaac Baker Brown llevó a cabo clitoridectomías -ablaciones de clítoris- en su clínica [...]. La ciencia legitimaba estas operaciones con el argumento de que eliminar el clítoris podía sanar trastornos tan variados como la incontinencia, las hemorragias uterinas, la histeria y la manía masturbatoria. Brown tuvo tanto éxito con sus prácticas, que en 1865 resultó elegido presidente del Colegio de Médicos de Londres. Durante el siguiente año escribió un libro en el que defendía la ablación del clítoris: On the Curability of Certain Forms of Insanity, Epilepsy and Hysteria in Females. (Blackledge 2003: 136)

La afición decimonónica a la extirpación quirúrgica de tejido genital para corregir lo que se consideran trastornos propios de la mujer (pero que eran rasgos normales de la sexualidad femenina) no se limitó a la escisión del clítoris o los labios de la vulva: los ovarios también cayeron bajo el escalpelo. Tan solo en el año 1855, en Gran Bretaña se practicaron más de doscientas ovariotomías, con un índice de mortalidad cercano al 50 por 100. (Blackledge 2003: 136)

En Estados Unidos, Francia y Alemania también se practicaba "die castration der Frauen". Fue tal el ansia mutiladora, que en 1866 un médico escribía lo siguiente en un diario británico: "Pronto se hará difícil encontrar alguna mujer que conserve la totalidad de sus órganos sexuales". (Blackledge 2003: 137)

Los párrafos anteriores ilustran que la justificación médica de la ablación genital venía a ser una persecución disfrazada o camuflada de la sexualidad femenina, en un intento por apartar definitivamente, de manera drástica, a las mujeres del hábito de la masturbación y explicando y diagnosticando gran número de males como resultado de tendencias o prácticas sexuales desviadas. Así pues, podemos observar que en diversas 
épocas históricas y comunidades se ha intervenido y se interviene de manera traumática sobre el cuerpo de la mujer por intereses de control sexual.

\section{El clítoris y la vagina dentada}

El análisis de los mitos nos ayuda a entender la forma en que el ser humano se aproxima a determinadas problemáticas y los procesos defensivos que utiliza para ocultar sus inquietudes y angustias. Llegado a este punto del artículo, quisiera comentar que el discurso justificador de la mutilación genital se ampara en argumentaciones estéticas, higiénicas e identitarias que no dejan de ser elementos encubridores de motivos inconscientes. Partamos de la mitología de los dogon, quienes sostienen que el ser humano nace con dos almas: "Mientras conserva el prepucio o el clítoris, soportes del principio de sexo contrario en el sexo aparente, masculinidad y feminidad tienen la misma fuerza" (Griaule 1966: 150), y en esas circunstancias no se sentiría interés por la procreación. El clítoris le impediría a la mujer aparearse con un hombre: "De la misma forma que Dios vio levantarse ante sí el órgano de la tierra, de la misma manera sería 'pinchado' el hombre que se uniera a una mujer sin excisión y discutida su presencia por el órgano que pretendería ser su igual" (Griaule 1966: 150).

En la cosmogonía de los dogon la tierra es un cuerpo femenino, cuya vagina es un hormiguero y su clítoris un termitero. Dios, que estaba solo, quiso unirse a la tierra, pero en el momento en que se encontraba próximo a ella, se alzó su termitero, impidiéndole el paso y mostrándole el sexo masculino. "No obstante, Dios es todopoderoso. Abate el termitero rebelde y se une a la Tierra sometida a la excisión” (Griaule 1966: 22).

Los dogon creen que la dualidad sexual supone la imposibilidad del apareamiento. Su mitología ilustra el miedo de los hombres a no poder consumar la relación. Su mitología expresaría la angustia que provoca en ciertos hombres el reconocimiento de todo aquello que puedan percibir de carácter fálico o masculino en las mujeres, por ejemplo, el clítoris. Y es por tal motivo que, sintiéndose amenazados por determinados 
aspectos (del cuerpo) de las mujeres, contemplan su modificación (corporal) como la solución para relacionarse con ellas sin problemas.

El clítoris, un órgano con infinidad de terminaciones nerviosas y que mediante su estimulación brinda a la mujer la posibilidad de experimentar gran placer sexual y llegar al orgasmo, ha sido demonizado en determinadas sociedades, considerándosele como un órgano peligroso cuyo contacto puede resultar fatal. Así, de acuerdo con ciertas creencias culturales, si durante el parto el clítoris toca la cabeza del niño este puede morir o quedar afectado con trastornos mentales. También se sostiene que el clítoris (un dardo según los bambara) puede dañar gravemente al hombre durante el momento del coito o incluso producirle la muerte. Cabe destacar que estas consideraciones acerca del clítoris (o las creencias de los dogon) remiten al mito de la vagina dentada. Con diversas derivaciones o variantes, en este mito que está extendido entre comunidades de todo el planeta, a lo largo y ancho de África, en América del Norte y del Sur, en Europa y en la India, se habla de mujeres o seres femeninos que poseen una vagina poblada o dotada con dientes, con capacidad para atrapar y devorar el pene, por lo que, el héroe de turno, se lanza a la labor de derribarlos o extirparlos, con la finalidad de conjurar la amenaza castradora de la vagina y pasar así a la posición de dominador en la relación (sexual). Veamos unos ejemplos:

En un relato toba-pilagá incluido por Lévi-Strauss [...] en Lo crudo y lo cocido, se habla de las mujeres de vagina dentada que bajan del cielo y roban carne a los cazadores. En otro mito de los matako (habitantes del Chaco), el héroe Carancho, valiéndose de una piedra, quitó la letal dentadura vaginal a estos seres, haciendo posible que los hombres pudieran copular. En la versión mítica del origen de las mujeres pilagá registrada por Newbery [...] se indica que comían por la boca "y entre las piernas"; el águila enseñaría a desdentarlas (con una piedra, según ha dicho) para que nacieran los primeros pilagá. (Báez-Jorge 2000: 113)

En el mito de la vagina dentada el héroe se acerca a la sexualidad como a un campo de batalla, y no de intercambio amoroso, donde su propósito radica en conseguir pleno gobierno sobre la figura femenina, hasta entonces dominadora de la relación: 
En una versión hindú se relata la historia de la hija de un Rakshaa (demonio) que tenía alargados y afilados dientes en su vagina. La presencia de un hombre la movía a convertirse en una bella y cautivadora doncella, para así seducirlo, cortarle el pene y comérselo lanzando posteriormente el resto del cuerpo a los tigres. En una oportunidad, en la densidad de la selva, conoció a siete hermanos [...]. Transcurrido un tiempo prudente sedujo al hermano mayor en un lecho cercano a la morada de los tigres, le mutiló el pene al joven, y arrojó su cuerpo como pábulo de felinos. De la misma forma procedió con los demás hermanos hasta que solo quedaba el benjamín. Sin embargo, cuando llegó el turno de este los dioses le ayudaron enviándole un sueño: si te vas con la joven lleva un tubo de hierro y en vez de hacer el amor con ella, introdúceselo en la vagina y destrúyele los dientes. Eso hizo el hermano menor, poniendo bajo su control a la hija de Rakshaa. (Capriles 1979)

Podemos afirmar que en los relatos mitológicos acerca de la vagina dentada el clítoris vendría a ser el diente que sobrevive o persiste incólume después de que los otros hubieran sido extirpados o arrancados. El mito de la vagina dentada representa la angustia del hombre de quedar atrapado y ser devorado durante el acto sexual con la mujer, por lo que, siguiendo con esta formulación metafórica, lo más seguro para él sería relacionarse con una mujer vaginalmente desdentada, sin ningún diente, esto es sin clítoris, completamente inofensiva y dócil. En este sentido, la ablación del clítoris se presenta como el mecanismo por el cual el hombre afectado por un gran complejo de castración intentaría hacer desaparecer el carácter amenazador del aparato genital femenino para convertirlo, en un cruel ejercicio de domesticación, en un espacio habitable o gobernable para el pene. Pero en el fondo, todos los intentos del hombre por dominar (sexualmente) a la mujer encubren su gran temor de no poder responder adecuadamente ante ella, de no estar a la altura de ella, de verse disminuido o quedar cuestionado en su virilidad, en su potencia sexual, en su masculinidad u hombría. Es por eso que, cuando en una sociedad se defiende la ablación del clítoris, tendría que preguntarse por los miedos del hombre, por el temor inconsciente que ese órgano genital (y, por consiguiente, la relación con la mujer) le infunde.

Por otra parte, podemos considerar que el complejo de castración no se circunscribe al ámbito específico de la sexualidad sino que además se extiende a otros ámbitos de la cotidianeidad. El temor a la mujer puede derivar en impotencia como 
también en su negación, en una masculinidad exacerbada o en afán de dominación. Hablamos de unos hombres que necesitan que las mujeres sean sumisas, dóciles, serviles, dependientes de ellos, para así sentirse poderosos y dominantes. La posibilidad de que ellas se manifiesten o desempeñen con suficiencia, poder y libertad les descoloca y desubica, les precipita al abismo de sus miedos masculinos de impotencia sexual y relacional. Lo que no ven o no quieren ver los hombres dominantes para con las mujeres es que las diferencias sexuales, el hecho de ser diferentes, no tiene que suponer desigualdad relacional ni ejercicio de poder de nadie sobre nadie. Creen o temen que las mujeres libres e independientes los devoren, los trastornen, los anulen, los dejen en evidencia o los conviertan en impotentes.

\section{Conclusiones}

Como hemos visto en este artículo, el objetivo principal de la mutilación genital femenina responde al deseo de controlar y dominar la capacidad sexual de la mujer. Un afán de control o dominación que denota un gran temor: que la mujer no mutilada genitalmente pueda sentirse insatisfecha con el grado de placer que obtiene y/o con el número de relaciones sexuales que mantiene con su esposo, o que el hombre quede devorado o subsumido por la capacidad sexual de la mujer. Un afán de dominación que remite a la inseguridad del hombre en su propia capacidad amatoria para con la mujer.

Es evidente que en las sociedades temerosas de la sexualidad (femenina) se idean diversos dispositivos orientados a la represión o reducción del apetito sexual. El clítoris es visto como un órgano de voluptuosidad cuyo tocamiento podría conducirle a la mujer a una sexualidad desbordante, desenfrenada, inmoral, en lugar de verse como un órgano por el cual poder disfrutar libremente y sin complejos del placer sexual. En estas sociedades no se contempla la gratificación sexual de la mujer al margen del propósito de la reproducción o de la satisfacción al hombre, como si el placer por el placer en la mujer fuera peligroso o subversivo para la estructuración social. Se pretende, exige y 
espera que el desempeño de la mujer en el área sexual lo sea desde la mera receptividad o pasividad. Mujer dócil, sumisa, obediente. Y complaciente. No demandante ni autónoma, pues a la mujer que busca la satisfacción libre de su sexualidad, saltándose las normas estrictas y asfixiantes de la sociedad, se le acusa de perversa o prostituta, como mala mujer. Dicho de otra manera, cuando en determinadas sociedades y/o épocas históricas la aceptación y adaptación de la mujer pasa por el control de su sexualidad, bajo la consideración de evaluaciones dicotómicas rígidas (mujer santa o pura versus mujer lasciva), ello es revelador del miedo del hombre a la mujer.

De todos modos, aunque no se llegue a practicar la mutilación genital, Wilhelm Reich nos advierte que las sociedades patriarcales desarrollan formas refinadas y eficaces de control sexual (mediante prohibiciones y estrictas medidas morales), cuyo resultado es un daño temprano en la capacidad de expresión sexual del ser humano, "en el sentido de la impotencia orgástica, no sin colgarse del cuello, al mismo tiempo, las neurosis, las perversiones y los delitos sexuales" (Reich 1932: 75). Teniendo en cuenta esta tesis, quisiera manifestar lo siguiente: todo afán de dominación (sexual) supone una respuesta patológica en el manejo de los temores con respeto a la persona con la que se desea mantener o ya se mantiene una relación mientras que la capacidad y oportunidad de participar en relaciones (sexuales) consensuadas, en busca de la satisfacción de todos sus participantes, redunda en el desarrollo personal y en las posibilidades de disfrutar y ser felices.

\section{Ideas para una propuesta preventiva}

Cuando abordamos el tema de la sexualidad en una determinada sociedad, hemos de tener en cuenta que las valoraciones y significaciones colectivas tienen gran repercusión en los individuos y en sus formas de expresión sexual. En este sentido, hay sociedades que se guían o conducen desde el respeto a las minorías sexuales y en defensa de las relaciones igualitarias entre hombres y mujeres mientras que otras 
sociedades en su conjunto, o en determinados subgrupos, se conducen mediante actitudes persecutorias, discriminatorias y gravemente limitadoras de la capacidad de expresión de sus integrantes en general o de determinados sujetos. En lo que respecta al tema que nos ocupa, el de la mutilación genital femenina, constituye un gran reto tratar de desarticular el discurso alienador que lo sustenta y que en determinadas grupos o comunidades puede estar fuerte e históricamente arraigado, siendo necesario un abordaje multidisciplinar e integral, que tendría que desarrollarse en diferentes vertientes (legal, sanitaria, educativa, sociocultural) y dirigirse a profesores, padres y madres, profesionales de la salud, políticos y líderes religiosos, periodistas, etc.

Es importante desarrollar actividades encaminadas a sensibilizar acerca del sufrimiento físico y psicológico de las niñas y mujeres que son víctimas de la mutilación genital, dando a conocer las graves limitaciones y dificultades que ello les puede generar a lo largo de sus vidas.

Se debe luchar contra todo tipo de mutilación genital realizado por razones no terapéuticas a las niñas y contra la que es forzosa para la población femenina adulta. Otra cuestión diferente es que entre mujeres adultas algunas de ellas decidan libremente someterse a una mutilación genital por motivos rituales o socioculturales, de manera semejante a como proceden ciertas mujeres de las sociedades occidentales que se someten a diversas cirugías (como son la vaginoplastia y la implantación de prótesis mamarias) con el objetivo de adecuarse a unos determinados cánones de belleza y sentirse sexual o corporalmente atractivas. O como cuando en las relaciones sadomasoquistas, en función del juego erótico de dominación-sumisión, y de manera consensuada, se busca o plantea el daño mental y/o físico, pudiendo llegar a concretarse mutilaciones corporales diversas.

Sabido es que la educación puede tener un papel conformador y transformador de conciencias y que, desarrollada desde la primera infancia, debe fomentar actitudes igualitarias, tolerantes y respetuosas para con el otro. Tratando de erradicar todas las formas de maltrato que, a veces, por el arraigo cultural, pueden pasar desapercibidas para bastantes personas. Por eso, si se desea llevar a cabo una intervención terapéutica 
y/o preventiva con estas personas, es necesario disponer de capacidad y talante para adentrarse empáticamente en sus propuestas y planteamientos ante la existencia, tratando de conocer cómo está estructurado su imaginario social. Y a este respecto la mitología y los ritos ofrecen información sumamente valiosa. Como sugiere Adriana Kaplan en diferentes artículos (véase, por ejemplo, Bedoya y Kaplan 2004, Kaplan y colaboradores 2006) debería realizarse un acercamiento antropológico a la realidad de los grupos en que se practica la mutilación genital, para así poder ser reconocidos como mediadores y poder trabajar eficientemente con sus integrantes las problemáticas que les afectan. En el tema que nos ocupa, una posibilidad de trabajo es preguntándose por los mitos y miedos sobre lavida sexual, ayudando a entender a la gente que la sexualidad es consustancial al ser humano y que todos y cada uno de nosotros tenemos derecho a vivirla en función de nuestros afectos y deseos y desde el respeto a nuestra integridad corporal y nuestra voluntad.

Uno de los motivos referidos por los defensores de la mutilación genital femenina es que dicha práctica favorece en la mujer su fidelidad y comportamiento virtuoso. De todos modos, habría que cuestionar tal forma de proceder, violatoria de los derechos humanos, además de poner de relieve que la fidelidad dependiente de la utilización de "un cinturón corporal de castidad" dista de ser una fidelidad auténtica.

Es sumamente interesante y útil plantear talleres sobre salud sexual, que pueden resultar de gran alcance terapéutico y preventivo, en los cuales hombres y/o mujeres puedan hablar libremente sobre sus inquietudes, miedos, inseguridades, deseos y fantasías con respecto a las personas del otro sexo. En los talleres a realizar con hombres una cuestión importante a abordar sería el temor a la figura femenina (Horney 1932), que si es reconocido y elaborado psíquicamente les ayudará a conocerse mejor, a explorar en sus recursos personales y a aproximarse respetuosa y empáticamente a las mujeres.

En los talleres sobre salud sexual habría que informar que toda persona, independientemente de su sexo, tiene derecho al placer y que el control del cuerpo (y la sexualidad) de la mujer afecta, obviamente, en la capacidad de expresarse y disfrutar de 
la mujer, y de manera secundaria también al hombre, puesto que la capacidad de gozo en la mujer no es limitadora sino acrecentadora de su capacidad de placer. Además, se debe tener en cuenta que la actitud controladora y dominadora del hombre sobre la sexualidad de la mujer constituye por sí misma una actitud neurótica en su capacidad de interacción.

Por último, considero importante realizar encuestas y entrevistas sobre actitudes y pensamientos con los grupos de hombres y mujeres con quienes se desarrollan tareas educativas, terapéuticas y/o preventivas, también con la población en general, para saber en qué medida se mantienen y modifican o evolucionan las formas de entender las relaciones interpersonales.

\section{Referencias bibliográficas}

Báez-Jorge, Félix. 2000. "Kauymáli y las vaginas dentadas". El héroe entre el mito y la historia. México: Centro de Estudios Mexicanos y Centroamericanos. 265-284.

Blackledge, Catherine. 2003. Historia de la vagina. Barcelona: Península.

Bedoya, María Helena y Kaplan, Adriana. 2004. "Las mutilaciones genitales femeninas en España: una visión antropológica, demográfica y jurídica”. Eds. J. Lucas y J. García Añon. Evaluating the Impact of Existing Legislation in Europe with Regard to FGM. Spanish Report, Universitat de Valencia. 1-37.

Capriles, Axel. 1997. "El miedo a las mujeres". Analítica Mensual, no 19. http://www.analitica.com/archivo/vam1997.09/soc04.htm [15 de julio de 2013].

Dirie, Waris. 2003 [1998]. Flor del desierto. Madrid: Maeva. 2005. Niñas del desierto. Madrid: Maeva.

El-Mouelhy, Mawaheb T. y R. Elise B. Johansen 2010. Men's and Women's Perceptions of the Relationship between Female Genital Mutilation and Women's Sexuality in Three Communities in Egypt. Geneva: World Health Organization, Department of Reproductive Health and Research.

Griaule, Marcel. 1966. Dios de agua. Barcelona: Alta Fulla.

Horney, Karen. 1932. "El miedo a la mujer”. Psicología femenina. Madrid: Alianza. 
Kaplan, A., P. Torán, M. H. Bedoya, K. Bermúdez, J. Moreno y B. Bolíbar. 2006. "Las mutilaciones genitales femeninas: reflexiones para una intervención desde la atención primaria”. Atención Primaria, vol. 38, n 2 : 122-126

OMS. 2012. "Mutilación genital femenina". Nota descriptiva $n^{\circ}$ 241. http: //www. who. int/mediacentre/factsheets/fs241/es/index.html

Reich, Wilhelm. 1932. La irrupción de la moral sexual. Buenos Aires: Homo Sapiens, 1983.

Tractenberg, Moisés. 1972. La circuncisión. Buenos Aires: Paidós. 